\title{
Assessment of Contractors' Mitigating Measures for Cost Overrun of Building Projects in South-Western Nigeria
}

\author{
Jacob A. B. Awolesi ${ }^{1}$, Jonathan K. Fabi ${ }^{1}$ \& Olubola A. Akinseinde ${ }^{1}$ \\ ${ }^{1}$ Department of Quantity Surveying, Federal Polytechnic, Ilaro, Nigeria \\ Correspondence: Jacob A. B. Awolesi, Department of Quantity Surveying, Federal Polytechnic, Ilaro, Nigeria. \\ Tel: 234-80-330-67045. E-mail: awolesibiodun@yahoo.co.uk
}

\author{
Received: August 25, 2015 Accepted: September 9, 2015 Online Published: November 23, 2015 \\ doi:10.5539/jsd.v8n9p139 URL: http://dx.doi.org/10.5539/jsd.v8n9p139
}

\begin{abstract}
The study examined the mitigating measures employed by contractors in southwest of Nigeria for cost overrun of building projects with a view to determining its adequacy and effectiveness. A mix of qualitative and quantitative research methods was adopted where data pertinent to the study were obtained through questionnaire survey on a sample of 32 project managers of medium sized construction firms selected from the list of 125 contractors on the register of Federation of Building and Civil Engineering Contractors located in South-West Nigeria using Simple Random Sampling method. Additional information was obtained from contracts bills of quantities and programme schedule to complement the data obtained from the questionnaire survey. Contract sums and final sums of building projects between 200 million Naira -1.7 billion Naira handled by respondents were also collected as secondary data. Statistical Package for Social Scientists (SPSS) was employed to analyse the data for descriptive statistics while manual approach was adopted for inferential statistics of t-test. The results obtained revealed that effective site management and supervision with the highest relative importance index (RII) for adequacy of the mitigation measures was at average level and the (RII) for the effectiveness of mitigation measures adopted by contractors was very low. It also revealed that there is significant difference between initial sums and final sums of building projects at $5 \%$ significance level where the mitigation measures were taken in to consideration. The study concluded that mitigation measures adopted by contractors have not been adequate and effective in curbing cost overrun of building projects in southwest Nigeria.
\end{abstract}

Keywords: building projects, contractors, cost overrun, mitigating measures

\section{Introduction}

That construction industry world-wide is be-devilled with cost overrun is reflected in the fact that many construction projects do not achieve their cost objective. According to Ade et al. (2013) Poor cost performance in construction project is a common problem resulting in significant amount of cost overrun. Cost escalation exists globally over the years and it has not decreased, thus it appears no learning seems to take place concerning the subject (Flyvbjerg, Holm and Buhl, 2014). As a result of the pivotal position and significance of cost in construction development chain, there had been concerted efforts among the stakeholders and researchers to curb overrun of cost on construction projects. Despite the invention of various project control tools/techniques and software, the problem persist and distorts the cost and time objectives of many construction projects according to Olawale and Sun (2010). Thus, in recent times, there have been numerous studies aimed at proffering solution to this seemingly intractable problem.

In the past, some researches carried out outside Nigeria (overseas) identified the factors influencing time and cost overrun generally (Kaming, 1997; Kumaraswamy and Chan, 1998; Frimpong et al., 2003; Assaf and Al-Heji, 2006; Al-Momani, 2000; Hsieh et al, 2004; Yogeswaran et al 1998; Akinsola, 1997) While in Nigeria, the few studies carried out were not different in their focus on the causes and effects of cost and time overruns on project out come. The study by Mansfield et al (1994) on 50 contractor, consultant and client organizations in Nigeria identified some factors causing delays and cost overruns. Studies on measures to curb the incidence of both cost and time overrun in Nigeria are scanty. Hence, this study is aimed at assessing the mitigating measures adopted by medium sized contractors in South-western Nigeria with a view to determining its adequacy and effectiveness at curbing the incidence of cost overrun. 


\subsection{Mitigating Measures for Cost Overrun}

Ahiaga-Dagbui \& Smith (2013) developed a model of data mining techniques combined with Artificial Neural Network (ANN) to check accuracy of cost estimation as one of the major factor for cost overrun.

Other measures proposed recently includes reference class forecasting and public sector accountability (Flyvbjerg 2007, 2008; Berechman and Chen, 2011; Cantarelli et al.,2012 cited in Lind, \& Brunes, 2014). The reference class forecasting uses the actual performance in a reference class to project accuracy by identifying relevant reference class of past and similar projects, establishing a probability distribution for the identified reference class and comparing the specific project with the reference class distribution to establish the likely outcome of the project. Although, Chevroulet, Giorgi and Reynaud (2012) in his study to predict a pattern for cost overruns, highlighted lack of reliable data for reference class forecasting or scenario analysis and suggested improvement in decision support before construction; management and monitoring during construction and feedback \& consolidation of knowledge after construction.

Rahman et al. (2013) suggested an improved site management and supervision of contractors to control cost overruns. Although important, but not efficient in mitigating cost overrun because cost overrun is initiated from the inception of a project according to Brunes and Lind (2013), he however pointed out that most cost overruns occur in the design and planning stage. Statistical analysis by Doloi (2013) suggested well-developed technical skills to control cost in modern projects.

Similar statistical distributions by Love et al. (2013) to a set of actual projects with different characteristics to predict cost overruns revealed no significant differences in cost overruns among projects with different procurement method.

According to Ade et al (2013), the following mitigating measures can be adopted to reduce or eliminate cost overrun of projects.

- $\quad$ Effective strategic planning
- $\quad$ Proper project planning and scheduling
- $\quad$ Prequent project meeting
- $\quad$ Use of experienced subcontract and Suppliers
- $\quad$ Use of appropriate construction methods
- $\quad$ Clear information and communication channel
- $\quad$ Frequent co-ordination between the parties
- $\quad$ Perform a preconstruction planning of project tasks and resources need.
- $\quad$ Development of human resources in the construction industry
- $\quad$ Comprehensive contract administration
- $\quad$ Systematic control mechanisms
Effective site management and supervision

\section{Method}

A questionnaire survey was conducted on a sample population of 45 project managers in medium sized contracting firms in southwest Nigeria using simple random sampling method. Thirty-two (32) hard copies of the questionnaire were retrieved in person, yielding a response rate of $71 \%$. The questionnaire elicits the following information about the respondents' particulars: Professional qualification, Working Experiences in the construction industry and the type of organization the respondents work. The likert scale of 1-4 was applied in assigning value to the data collected for adequacy of the mitigating measures. The scale is: 1-not adequate, 2-less adequate, 3-adequate, and 4-very adequate for the adequacy of the measures. In addition, 1-not effective, 2-less effective, 3 - effective, and 4 - most effective were employed for the effectiveness of the measures. The scales were converted to relative importance index (RII) using the following formula, as adopted by Kumaraswany and Chan (1997, 1998), Assaf et al (1995) and Iyer and Jha (2005):

$$
\text { Relative importance index }(\mathrm{RII})=\sum \mathrm{w} \div(\mathrm{H} \mathrm{x} \mathrm{N})
$$

Where $\mathrm{w}$ is the total weight given to each factor by the respondents, which ranges from 1 to 4 and is calculated 
by an addition of the various weightings given to a factor by the entire respondent, $H$ is the highest ranking available (i.e. 4 in this case) and $\mathrm{N}$ is the total number of respondents that have answered the question.

\subsection{Test of Hypothesis}

Null Hypothesis $\left(\mathbf{H}_{\mathbf{0}}\right)$ : There is no significant difference between the contract sum and the completion sum of building projects.

Alternative Hypothesis $\left(\mathbf{H}_{\mathbf{I}}\right)$ : There is significant difference between the contract sum and the completion sum of building projects.

The test of hypothesis for this study was based on $5 \%$ significance level and was adopted to test the significance of the difference between the initial and final contract sums of the building projects executed by medium sized contracting firms, to establish the effectiveness of the adopted measures.

\subsection{The t-Statistics}

This was used for 15 samples of building projects on which the contracting firms have employed mitigation measures to test its effectiveness. Its use was based on the premise that t-statistic was applicable for sample size that was less than 30. According to Lucey (1996). For t-statistic,

$$
\begin{gathered}
\mathrm{t}-\text { calculated }=\frac{Y-X}{s_{(Y-X)}} \\
S_{(Y-X)}=\sqrt{\frac{(n y-1) S_{y}^{2}+(n x-1) S_{x}^{2}}{n_{y}+n_{x}-2}\left(1 / n_{y}+1 / n_{x}\right)}
\end{gathered}
$$

$\mathrm{x}$ and $\mathrm{y}$ are two variables

$\mathrm{X}$ and $\mathrm{Y}$ are the mean values

$\mathrm{N}=$ Samples Size

$\mathrm{S}_{\mathrm{y}}$ and $\mathrm{S}_{\mathrm{x}}=$ Standard deviation of $\mathrm{y}$ and $\mathrm{x}$ respectively

The decision is that if the calculated t-statistic equal to or greater than t-critical respectively, then the null hypothesis may be rejected at the level of significant difference between the contract sums and the completion sums.

\subsection{Data Analysis}

The Statistical Package for Social Sciences (SPSS) and manual method were used for the analysis. The demographic details of the respondents were produced and the mean ranks of the identified mitigating measures were used for the ranking in the analysis. Inferential statistical tool of t-statistic was also used in the analysis to investigate variability in the initial and final sum of building projects where mitigating measures were adopted by medium sized category of contractors in curbing cost overrun.

\section{Results}

Thirty-two (32) questionnaires were collected back from respondents and used for the analysis.

The demographic details of the respondents are as presented in table 1 . 
Table 1. Demographic details

\begin{tabular}{|c|c|c|c|c|c|}
\hline & Variables & Frequency & $\begin{array}{l}\text { Cumulative } \\
\text { Frequency }\end{array}$ & Percentage & $\begin{array}{l}\text { Cumulative } \\
\text { Percentage }\end{array}$ \\
\hline \multirow[t]{3}{*}{1} & Type of organisation / Firm $(\mathrm{N}=32)$ & & & & \\
\hline & Expatriate & 14 & 14 & 43.75 & 43.75 \\
\hline & Indigenous & 18 & 32 & 56.25 & 100.00 \\
\hline \multirow[t]{9}{*}{2} & $\begin{array}{l}\text { Professional } \\
\text { Grades }(\mathrm{N}=32)\end{array}$ & & & & \\
\hline & Architects & 3 & 3 & 10 & 10 \\
\hline & Builders & 7 & 10 & 22 & 32 \\
\hline & Quantity Surveyors & 8 & 18 & 25 & 57 \\
\hline & Mechanical Engineers & 3 & 21 & 9 & 66 \\
\hline & Civil Engineers & 5 & 26 & 15 & 81 \\
\hline & Estate Surveyors & 3 & 29 & 10 & 91 \\
\hline & Electrical Engineers & 2 & 31 & 6 & 97 \\
\hline & Others & 1 & 32 & 3 & 100.00 \\
\hline \multirow[t]{5}{*}{3} & $\begin{array}{l}\text { Work Experiences in the } \\
\text { Construction }\end{array}$ & & & & \\
\hline & Industry $(\mathrm{N}=32)$ & & & & \\
\hline & Less than $10 \mathrm{yrs}$ & 13 & 13 & 41 & 41 \\
\hline & $10-20 \mathrm{yrs}$ & 11 & 24 & 34 & 75 \\
\hline & $21-30 \mathrm{yrs}$ & 8 & 32 & 25 & 100.00 \\
\hline
\end{tabular}

Source: Field survey, 2015

Table 1 shows the demographic details of the respondents; $59 \%$ has put over 10 years working experience in the construction industry and are registered members of their respective professional bodies. This shows that data supplied by these categories of respondents is reliable

Table 2. Adequacy of mitigating measures adopted by medium sized contractors on cost overrun

\begin{tabular}{lll}
\hline Mitigating measures & RII & Ranking \\
\hline 1. Effective site management and supervision & 0.65 & $1 \mathrm{st}$ \\
2. Proper project planning and scheduling & 0.62 & $2 \mathrm{nd}$ \\
3. Clear information and communication channel & 0.60 & $3 \mathrm{rd}$ \\
4. Use of experienced subcontractors and Suppliers & 0.56 & 4 th \\
5. Use of appropriate construction methods & 0.54 & 5 th \\
6. Proper emphasis on past experience & 0.50 & 6 th \\
7. Frequent co-ordination between the parties & 0.50 & 6 th \\
8. Perform a preconstruction planning of project tasks and resources need & 0.50 & 6 th \\
9. Use of up-to-date technology utilization & 0.46 & 9 th \\
10. Comprehensive contract administration & 0.43 & 10 th \\
11. Frequent project meeting & 0.42 & 11 th \\
12. Development human resources in the construction industry & 0.40 & 12 th \\
13. Effective strategic planning & 0.38 & 13 th \\
14. Systematic control mechanism & 0.30 & 14 th \\
\hline
\end{tabular}

Source: Field survey, 2015. 
Table 2 shows the RII on the adequacy of the mitigating measures on the cost overrun of building projects in the study area. Effective site management and supervision has the highest RII of 0.65 , followed by proper project planning and scheduling 0.62 followed by others. The overall implication of this is that the RII is low generally; the use of these measures has not been adequate and has resulted in cost overrun of most building projects.

Table 3. Effectiveness of mitigating measures adopted by medium sized contractors on cost overrun

\begin{tabular}{lll}
\hline Mitigating measures & RII & Ranking \\
\hline 1. Effective site management and supervision & 0.60 & $1 \mathrm{st}$ \\
2. Proper project planning and scheduling & 0.58 & $2 \mathrm{nd}$ \\
3. Clear information and communication channel & 0.54 & $3 \mathrm{rd}$ \\
4. Use of experienced subcontractors and Suppliers & 0.50 & 4 th \\
5. Use of appropriate construction methods & 0.46 & 5 th \\
6. Proper emphasis on past experience & 0.42 & 6 th \\
7. Frequent co-ordination between the parties & 0.40 & 6 th \\
8. Perform a preconstruction planning of project tasks and resources need & 0.36 & 6 th \\
9. Use of up-to-date technology utilization & 0.34 & 9 th \\
10. Comprehensive contract administration & 0.32 & 10 th \\
11. Frequent project meeting & 0.26 & 11 th \\
12. Development human resources in the construction industry & 0.26 & 12 th \\
13. Effective strategic planning & 0.24 & 13 th \\
14. Systematic control mechanism & 0.20 & 14 th \\
\hline
\end{tabular}

Source: Field survey, 2015

Table 3 shows the RII on the effectiveness of the mitigating measures on the cost overrun of building projects in the study area. Effective site management and supervision has the highest RII of (0.60), followed by proper project planning and scheduling $(0.58)$ followed by clear information and communication channel $(0.54)$. The overall RII is too low which implies that there has not been effectiveness in the use of mitigating measures and has resulted in cost overrun of most building projects.

Evaluation of the variability between the contract sums and the completion costs of projects where mitigation measures were used for building projects by medium sized contractors in southwestern Nigeria.

\section{Hypothesis 1:}

Null Hypothesis $\left(\mathbf{H}_{\mathbf{0}}\right)$ : There is no significant difference between the contract sum and the completion cost of building projects.

Alternative Hypothesis $\left(\mathbf{H}_{\mathrm{I}}\right)$ : There is significant difference between the contract sum and the completion cost of building projects. 
Table 4. Building projects with contract sums and completion costs range between 200 million to 1.7 billion Naira

\begin{tabular}{lllll}
\hline Project & $\mathbf{X}$ (Million) & $\mathbf{Y}$ (Million) & $\mathbf{X}^{\mathbf{2}}$ & $\mathbf{Y}^{\mathbf{2}}$ \\
\hline 1 & 228 & 407 & 51984 & 165649 \\
2 & 212 & 389 & 44944 & 155321 \\
3 & 652 & 956 & 425104 & 913936 \\
4 & 517 & 927 & 267289 & 859329 \\
5 & 957 & 1655 & 915849 & 2,739025 \\
6 & 201 & 364 & 40401 & 132496 \\
7 & 127 & 248 & 16129 & 61504 \\
8 & 428 & 898 & 183184 & 806404 \\
9 & 613 & 963 & 375769 & 927369 \\
10 & 625 & 1090 & 390625 & 1188100 \\
11 & 125 & 198 & 15625 & 39204 \\
12 & 457 & 723 & 208849 & 522729 \\
13 & 205 & 360 & 42025 & 129600 \\
14 & 251 & 379 & 63001 & 143641 \\
15 & 426 & 658 & 181476 & 432964 \\
Total & $\mathbf{6 , 0 2 4}$ & $\mathbf{1 0 , 2 1 5}$ & $\mathbf{3 , 2 2 2 , 2 5 4}$ & $\mathbf{9 , 2 1 7 , 2 7 1}$ \\
\hline
\end{tabular}

Source: Field survey, 2015

From Table $4 \mathrm{t}-\mathrm{cal}=2.48$, and $\mathrm{t} \alpha / 2=1.753$. Since $\mathrm{t}$ cal $<\mathrm{t} \alpha / 2$, reject the null hypothesis and, then accept the alternate hypothesis that there is significant difference between the contract sum and the completion cost of projects where mitigation measures were used for building projects by medium size contractors.

\section{Discussion}

Table 1 shows the demographic details of the respondents to this study. The number of years they have put in the industry and the projects they have handled shows that the information supplied by them are adequate and reliable for the study.

Table 2 shows the RII on the adequacy of the mitigation measures on the cost overrun of building projects in the study area. Effective site management and supervision has the highest RII of 0.65 , followed by proper project planning and scheduling 0.62 . The RII of majority of other mitigating measures are slightly above 0.50 . The overall implication of this is that the RII is on the average level. Generally, the use of these measures has not been adequate and has not been able to curb cost overrun of building projects in the study area.

Table 3 shows the RII on the effectiveness of the mitigation measures on the cost overrun of building projects in the study area. Effective site management and supervision has the highest RII of (0.60), followed by proper project planning and scheduling (0.58) followed by clear information and communication channel $(0.54)$. The overall RII is low for the effectiveness of these mitigation measures, which implies that there has not been effectiveness in the use of mitigation measures in curbing cost overrun of building projects.

The result from table 4 shows that $\mathrm{t}$-cal. $=2.48$ and $\mathrm{t}$-tabulated $=1.753$. Reject the null hypothesis and accept the alternate hypothesis that there is significant difference between the contract sum and the completion cost of projects where mitigation measures were used for building projects by medium sized contractors. This confirms the results obtained in Table 3 that these mitigation measures have not been effective in curbing cost overruns of building projects in the southwest Nigeria.

\section{Conclusions}

This paper has been able to assess the adequacy and effectiveness of mitigation measures adopted by medium size contractors to curb cost overrun of building projects in the south-western part of Nigeria. The following conclusions have been drawn: 
The adequacy of these mitigation measures has been on the average level. These mitigation measures have not been effective in curbing cost overruns of building projects in the study area.

\section{References}

Ade, A. A., Aftab, H. M., Ismail, A., \& Ahmad, T. A. (2013). Controlling Cost Overrun Factors in Construction Projects in Malaysia. Journal of Applied Science, Engineering and Technology, 5(8), 2621-2629.

Ahiaga-Dagbui, D. D., \& Smith, S. D. (2013). My cost runneth over: data mining to reduce construction cost overrun. In S. D. Smith, \& D. D. Ahiaga-Dagbui (Eds.), $29^{\text {th }}$ Annual ARCOM conference, 2-4 September, 2013, Reading, UK Association of Researchers in Construction Management 559-568.

Al-Momani, A. (2000). Construction Delay: A Quantitative Analysis. International Journal of Project Management, 3(8), 21-29. http://dx.doi.org/10.1016/s0263-7863(98)00060-x

Berechman, J., \& Chen, L. (2011). Incorporating Risk of Cost Overruns into Transportation Capital Projects Decision-Making. Journal of Transport Economics and Policy, 45(1), 83-104.

Cantarelli, C., Flyvbjerg, B., Molin, E. J. E., \& van Wee, B. (2012). Cost Overruns in Large-scale Transportation Infrastructure Projects: Explanations and Their Theoretical Embeddedness. European Journal of Transport and Infrastructure Research, 10(1), 5-18.

Chevroulet, T., Giorgi, L., \& Reynaud, C. (2012). New Approach for the Assessment of High-Speed Rail Projects and How to Contain Cost Overruns: Lessons from the EVA-TREN Project. Journal of Infrastructure Systems, 18, 297-304. http://dx.doi.org/10.1061/(ASCE)IS.1943-555X.0000111

Doloi, H. (2013). Cost Overruns and Failure in Project Management: Understanding the Roles of Key Stakeholders in Construction Projects. Journal of Construction Engineering and Management, 139, 267-279. http://dx.doi.org/10.1061/(ASCE)CO.1943-7862.0000621

Flyvbjerg, B. (2007). Policy and planning for large infrastructural projects: problems, causes and cures, Environment and Planning. Planning and Design, 34, 578-597. http://dx.doi.org/10.1068/b32111

Flyvbjerg, B. (2008). Curbing Optimism Bias and Strategic Misrepresentation in Planning: Reference Class Forecasting in Practice. European Planning Studies, 16(1), 3-21. http://dx.doi.org/10.1080/09654310701747936

Flyvbjerg, B., Holm, M. K., \& Buhl, S. (2014). What causes Cost Overrun in Transport Infrastructure Projects. Transport Reviews, 24(1), 13-18.

Frimpong, Y., Oluwoye, J., \& Crawford, L. (2003). Causes of Delay and Cost Overrun in Construction of Groundwater Projects in Developing Countries. International Journal of Project Management, 21, 321-326. http://dx.doi.org/10.1016/S0263-7863(02)00055-8

Hsieh, T., Lu, S., \& Wu, C. (2004). Statistical Analysis of Causes of Change Orders in Metropolitan Public Works. International Journal of Project Management, 22(8), 679-686. http://dx.doi.org/10.1016/j.ijproman.2004.03.005

Kaming, P. F., Olomolaye, P. O., Holt, G. D., \& Harris, F. C. (1997). Factors Influencing Construction Cost and Time Overrun on High-rise Project in Indonesia. Construction Management and Economics, 15, 83-94. http://dx.doi.org/10.1080/014461997373132

Kumaraswamy, M., \& Chan, D. (1998). A comparative study of causes of time overrun in Hong Kong Construction Projects. International Journal of Project Management, 15(1), 55-63.

Lind, H., \& Brunes, F. (2014). Policies to avoid cost overruns in infrastructure projects: critical evaluations and recommendations. Australasian Journal of Construction Economics and Building, 14(3), 74-85. http://dx.doi.org/10.5130/ajceb.v14i3.4151

Love, P. E. D., Wang, X., Sing, C., \& Tiong, R. (2013). Determining the Probability of Project Cost Overruns. Journal of Construction Engineering and Management, 139, 321-330. http://dx.doi.org/10.1061/(ASCE)CO.1943-7862.0000575

Mansfield, N., Ugowu, O., \& Doran, T. (1994). Causes of Delay and Cost Overruns in Nigerian Construction

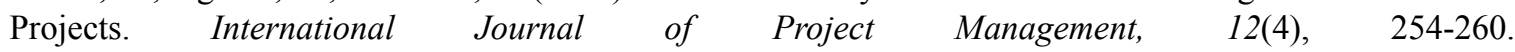
http://dx.doi.org/10.1016/0263-7863(94)90050-7 
Olawale, Y. A., \& Sun, M. (2010). Cost and Time Control of Construction Projects Inhibiting Factors and Mitigating Measures in practice. Construction Management and Economies, 28(5), 509-526. http://dx.doi.org/10.1080/01446191003674519

Rahman, I. A., Memon, A. H., Azis, A., \& Abdullah, N. (2013). Modeling Causes of Cost Overrun in Large Construction Projects with Partial Least Square-SEM Approach: Contractor's Perspective. Research Journal of Applied Sciences, Engineering and Technology, 5(6), 1963-1972.

Yogeswaran, K., Kumaraswamy, M., \& Miller, D. (1998). Claims for Extension of Time in Civil Engineering Projects. Construction Management and Economics, 16(3), 283-293. http://dx.doi.org/10.1080/014461998372312

\section{Copyrights}

Copyright for this article is retained by the author(s), with first publication rights granted to the journal.

This is an open-access article distributed under the terms and conditions of the Creative Commons Attribution license (http://creativecommons.org/licenses/by/3.0/). 